\title{
Effect $\mathrm{TiO}_{2}$ of Made of Ash Fly on Crystallization Activation Energy and Index
}

\author{
Feng $\mathrm{Li}^{1, \mathrm{a}}$, Xiangdong Liu ${ }^{1}$ \\ ${ }^{1}$ Inner Mongolia University of Technology in aimin St. Hohhot, China
}

\begin{abstract}
In this work, CAS system glass-ceramics with different components were prepared by a high temperature melting method. The high alumina fly ash and quartz sand were used as the main raw materials in Inner Mongolia where they were very rich and cheap. The nucleation agent was $\mathrm{TiO}_{2}$. According to the thermodynamics calculation, the reaction trend of the new phase transformation was compared. The nucleation and crystal growth rate were analyzed based on the point of dynamics. The activation energy and crystallization index were calculated by making use of an equation. With increasing the content of $\mathrm{TiO}_{2}$, the activation energy and index of crystallization of glass ceramics firstly increased to the maximum 1.95 , then deceased. The content of $\mathrm{TiO}_{2}$ had an optimal value of about $8 \%$. Under this condition, the activation energy of crystallization reached to the minimum $225.87 \mathrm{KJ} / \mathrm{mol}$. and the crystals precipitated more easily.
\end{abstract}

\section{Submitting the manuscript}

The first application of fly ash to the glass industry in the United States was EILENJ.DeGulro and other researchers, and later Italian researcher R.Cioffi and other researchers, in 1994, earliest prepared the main crystal phase of $\mathrm{LiAlSiO}_{4}$ and magnesium and lithium silicatebased in glass-ceramics by using fly ash in power plant. With the depth and the progressive development of these studies in order to obtain better performance, various types of nucleating agents were introduced. Among them, the nucleating agents of $\mathrm{TiO}_{2}, \mathrm{P}_{2} \mathrm{O}_{5}$ have a relatively large number of applications and so on. Although the previous studies of $\mathrm{TiO}_{2}$ have been done so much, but still not very thorough, and it needs to be further studied. In this paper, power plant fly ash and silica sand was used to produce glass ceramics, with $\mathrm{TiO}_{2}$ as nucleating agents, the influence of $\mathrm{TiO}_{2}$ on the crystallization activation energy and crystallization index are studied to analyze the reaction mechanism and explore the optimal nucleation agent ratio. The test used the differential thermal analysis method to calculate the glass crystallization activation energy, according to the thermal analysis results, it could be theoretically better used to analyze the formation mechanism and crystallization process characteristics of the glass. The differential thermal analysis method can also be used in studying the kinetics of the solid phase transformations, it is possible to study the activation energy of glass transformation from amorphous to crystalline state ${ }^{[1-5]}$ by differential thermal analysis methods. This work uses the most widely used Owaza formula derived based on the theory of thermal analysis and JMA formula to calculate the following activation energy formula:

\footnotetext{
a Li feng: lifeng2010@163.com
}

$$
\ln \alpha=-\frac{E}{R T_{P}}+C
$$

Wherein TP is the crystallization exothermic peak temperature in the DTA curve, $\mathrm{C}$ is a constant. This formula shows: According to $\ln \alpha$ to 1 / TP, the graphics must be made with a slope rate of -E / R of a straight line to find the slope rate of the line and the activation nuclear energy $E$ can be calculated ${ }^{[6-11]}$.

Crystal growth index $\mathrm{n}$ can be calculated by AugisBennett equation:

$$
\mathrm{n}=\frac{2.5 \mathrm{RT}}{\Delta \mathrm{T} \cdot \mathrm{E}}
$$

$\Delta \mathrm{T}$ : Temperature difference of FWHM corresponding to the maximum crystallization exothermic peak in DSC. T: Highest crystallization temperature in the DSC. E: Crystallization activation energy of glass. R: Gas constant, $8.31 \mathrm{~J} /(\mathrm{mol} \bullet \mathrm{K})$.

\section{Test Programs}

This test used fly ash after combustion in a power plant in Inner Mongolia power generation as the main raw material. The main chemical components are shown in Table 1, the raw material quartz sand quartz content of $97.4 \%$. The cosolvent $\mathrm{CaO}$ and $\mathrm{NaOH}$ are pure chemical reagents.

Table 1. Chemical components of ash fly(\%,mass fraction)

\begin{tabular}{cccccc}
\hline $\mathrm{Al}_{2} \mathbf{O}_{3}$ & $\mathrm{SiO}_{2}$ & $\mathbf{C a O}$ & $\mathrm{Fe}_{2} \mathbf{O}_{3}$ & $\mathrm{TiO}_{2}$ & Others \\
\hline $45.4 \%$ & $47.2 \%$ & $1.9 \%$ & $2.8 \%$ & $1.4 \%$ & $1.3 \%$ \\
\hline
\end{tabular}




\subsection{Preparation of Glass Ceramics}

According to the research results made before the results of this study and the CAS phase diagram, the ingredients are shown in Table 2 below. Weigh formulated various raw materials for milling mixing well after loading corundum crucible using the preheating furnace at $900{ }^{\circ} \mathrm{C}$, and then into the silicon-molybdenum high-temperature furnace at $3{ }^{\circ} \mathrm{C} / \mathrm{min}$ to rise to $1500{ }^{\circ} \mathrm{C}$ were heated for $4 \mathrm{~h}$, the molten homogeneous solution was rapidly poured into the glass in refractory abrasive molding preheated at $400{ }^{\circ} \mathrm{C}$, casted a square sample $80 \mathrm{~mm} \times 80 \mathrm{~mm} \times 8 \mathrm{~mm}$, air-cooled to room temperature and demoulded, and then immediately placed in an incubator-type resistance furnace for the stress relief annealing at $500{ }^{\circ} \mathrm{C}$. The glass samples cooled were crushed in an agate mortar into the glass powder samples for DSC curve by HSC-1 differential scanning calorimeter to measure at a high purity nitrogen atmosphere, in order to determine the glass transition temperature and crystallization temperature and crystallization conditions of samples with the different ingredients. During the DSC test, $\mathrm{Al}_{2} \mathrm{O}_{3}$ crucible was chosen as the reference, with a heating rate of $10{ }^{\circ} \mathrm{C} / \mathrm{min}$ and the heating temperature in the range from room temperature $20{ }^{\circ} \mathrm{C} \sim 1200{ }^{\circ} \mathrm{C}$.

Table 2. Mass ratio of raw materials(mass: \%)

\begin{tabular}{cccccc}
\hline No. & ash fly & $\begin{array}{c}\text { Quartz } \\
\text { sand }\end{array}$ & $\mathrm{NaOH}$ & $\mathrm{CaO}$ & $\mathrm{TiO}_{2}$ \\
S0 & 30 & 50 & 10 & 30 & 0 \\
S1 & 28.5 & 47.5 & 9.5 & 28.5 & 6 \\
S2 & 27 & 45 & 9 & 27 & 12 \\
S3 & 25.5 & 42.5 & 8.5 & 25.5 & 18 \\
\hline
\end{tabular}

\subsection{Test results}

\subsubsection{Endothermic Peak Tp of DSC Curves at Different Heating Rates}

According to Owaza equations, by the use of DSC curves at different heating rate measurement, glass crystallization activation energy $E$ of the sample can be calculated, the values of the activation energy $E$ of the samples can be used to measure the crystallization ability of the glass. Larger E values represent the crystallization ability of glass samples weaker, the more the stability of the sample, the less likely the glass crystallization; on the contrary, the smaller the value of $\mathrm{E}$, the glass crystallization ability is stronger, the less stability of the sample. The activation energy of the samples will change with their components and the additions. When the sample is added a certain content of nucleating agents, its crystallization activation energy will reduce, but when its content exceeds a certain limit, its value of the activation energy will increase. So in order to try to determine the influence on the samples with the different content of agents on the activation energy of S0 $\sim$ S3 samples, the DSC curves of the samples was measured at the different measured speeds of $5{ }^{\circ} \mathrm{C} / \mathrm{min}, 10{ }^{\circ} \mathrm{C} / \mathrm{min}, 15{ }^{\circ} \mathrm{C} / \mathrm{min}$. The measurement results are shown in Figure 9.1 to 9.15. It can be obtained from the above DSC curve Tp value for each sample as samples at different heating rates shown in Table 3:

Table 3. Tp values of samples with different heat rates

\begin{tabular}{cccc}
\hline No. & $\alpha=5^{\circ} \mathrm{C} / \min$ & $\alpha=10^{\circ} \mathrm{C} / \min$ & $\alpha=15^{\circ} \mathrm{C} / \mathrm{min}$ \\
\hline S0 & $1048^{\circ} \mathrm{C}$ & $1079^{\circ} \mathrm{C}$ & $1093^{\circ} \mathrm{C}$ \\
S1 & $1030^{\circ} \mathrm{C}$ & $1068^{\circ} \mathrm{C}$ & $1089^{\circ} \mathrm{C}$ \\
S2 & $989^{\circ} \mathrm{C}$ & $1030^{\circ} \mathrm{C}$ & $1057^{\circ} \mathrm{C}$ \\
S3 & $1010^{\circ} \mathrm{C}$ & $1046^{\circ} \mathrm{C}$ & $1066^{\circ} \mathrm{C}$ \\
\hline
\end{tabular}

\subsubsection{Calculation of Activation Energy and Crystallization Index}

According to Owaza equation (1), the heating rate and the corresponding endothermic peak temperature were substituted into this equation, the activation energy of different samples was calculated, the calculation process and the results are shown in Fig.1.
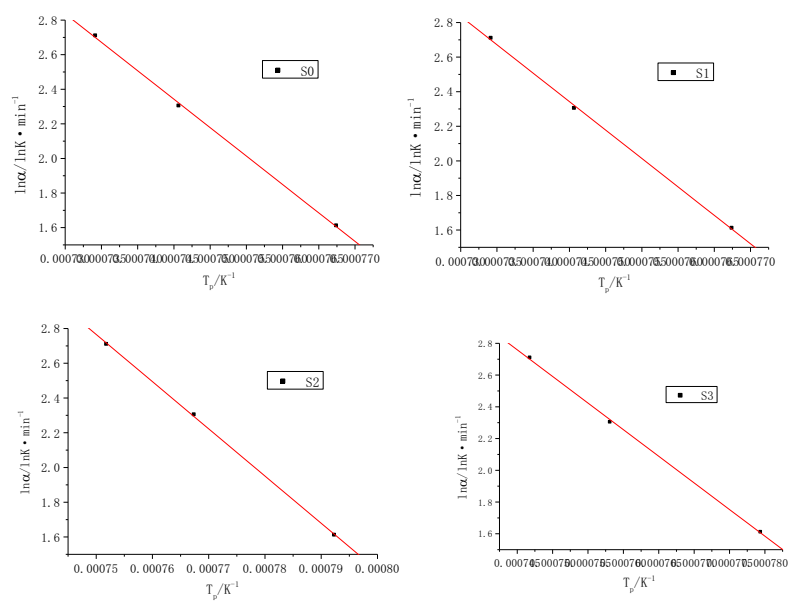

Fig.1 Fitting line of crystallization temperature versus heating rate

According to the relationship $\ln \alpha$ to $\frac{1}{\mathrm{TP}}$ and the graphs made in a diagonal pattern are shown in Figure 1, the activation energy obtained is shown in Table 4.

Table 4 Activation energy $\mathrm{E}$ and parameter $\mathrm{n}$ of samples

\begin{tabular}{cccc}
\hline No. & $\mathrm{TiO}_{2}(\%)$ & $\mathrm{E}\left(\mathrm{KJ} \cdot \mathrm{mol}^{-1}\right)$ & $\mathrm{n}$ \\
\hline $\mathrm{S} 0$ & 0 & 366.08 & 1.49 \\
$\mathrm{~S} 1$ & 5 & 273.33 & 1.73 \\
$\mathrm{~S} 2$ & 10 & 225.87 & 1.95 \\
$\mathrm{~S} 3$ & 15 & 278.87 & 1.63 \\
\hline
\end{tabular}

According Augis-Bennett equation (2) to calculate the crystallization index $\mathrm{n}$, the calculation results are shown in Table 4. As can be seen from Table 4, with the increase of content of nucleating agent in the sample glass, its crystallization energy firstly reduces then increases. The crystallization index $\mathrm{n}$ increases firstly then decreases. 
Curve fitting (as shown in Table 4 and shown in Fig. 2) can be seen by the results of the activation energy and the activation energy calculated: according to the DSC curve calculated in the samples S0, S1, S3, their activation energy values are greater than $\mathrm{S} 2$ value, that is, when the content of $\mathrm{TiO}_{2}$ is less, the glass crystallization activation energy is higher; when adding a certain amount of $\mathrm{TiO}_{2}$, with the increase of its content, the activation energy of the glass gradually reduces, when the content of $\mathrm{TiO}_{2}$ increases to $10 \%$, the activation energy reduces to a minimum for $225.87 \mathrm{KJ} \cdot \mathrm{mol}^{-1}$; but when the content of $\mathrm{TiO}_{2}$ continues to increase, the activation energy increases, when the content of $\mathrm{TiO}_{2}$ increases to $12.5 \%$, its activation energy increases to $278.87 \mathrm{KJ} \cdot \mathrm{mol}^{-1}$. The above test results show that $\mathrm{TiO}_{2}$ can promote the crystallization ability of the system, but there is an optimum amount in promoting their glass crystallization.
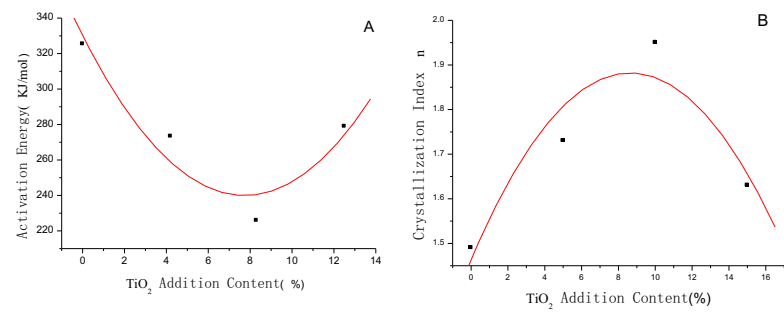

Fig. 2 Plot of the crystallization activation energy and parameter $n$ versus $\mathrm{TiO}_{2}$ content

By different crystallization indexes of contents of $\mathrm{TiO}_{2}$, when the $\mathrm{TiO}_{2}$ content is lower, crystallization index is 1.73. With the increase of $\mathrm{TiO}_{2}$ content, the crystallization index increases, when the content of $\mathrm{TiO}_{2}$ increases to $10 \%$, the crystallization index reaches a maximum value of 1.95 . But then $\mathrm{TiO}_{2}$ content increases, the crystallization index of the glass decreases. The crystallization index decreases to 1.64 when the content of $\mathrm{TiO}_{2}$ increases to $12.5 \%$.

\section{Result Analysis}

The difficulty of glass crystallization is influenced on the one hand by the kinetics of crystallization, on the other hand affected by the crystallization thermodynamics. Although at low temperature, the free energy difference of glass phase and crystal phase is larger, and phase transformation driving force is larger, from the thermodynamics of crystallization of glass, its crystallization trend is relatively large, it is conducive to the crystallization. But because glass is a mesh structure, glass has a high viscosity and atomic diffusion difficulty, in the aspect of the glass crystallization kinetics, the crystallization resistance is higher. Crystallization thermodynamics barriers of a glass mainly depends on the nuclei and the properties and composition of the phase around them, the kinetic barrier is mainly determined by the number of critical nuclei in the unit volume and the number of atoms to spread the critical nuclei. When the content of nucleating agent $\mathrm{TiO}_{2}$ is less or without nucleating agent, the nucleation requires the higher energy, the atomic diffusion activation energy can be met only at higher temperatures, so the nucleation and crystallization of the glass requires higher temperature. Adding a certain amount of nucleating agent $\mathrm{TiO}_{2}$, the transition of the crystal structure of the nucleating agents $\mathrm{TiO}_{2}$ occurs from high to low temperature. At high temperatures, $\mathrm{TiO}_{2}$ exists in four ligands $\left[\mathrm{TiO}_{4}\right]$ state and participates silicone network, so it is miscible with the melt well. And this tetrahedron structure is unstable, when the base glass is heat-treated, the unstable tetrahedral structure $\left[\mathrm{TiO}_{4}\right]$ will rearrange to form a stable hexacoordination structure $\left[\mathrm{TiO}_{6}\right]$. Due to differences in the tetrahedron structure of the glass and the hexacoordination $\left[\mathrm{TiO}_{6}\right]$ structure which the glass network is not very melt well with, the phase separation occurs in the glass melt to form new nuclei. When these nuclei and other oxides in the glass melt combine to form a new crystal phase which is different from the glass structure. When the nucleating agent is added into the glass, the crystallization activation energy of glass depends on the energy of the nucleating agent to form a new phase. The degree of difficulty of the crystallization activation energy of the basis glass added $\mathrm{TiO}_{2}$ as nucleating agents depends on forming new phase and breakage of the Ti-O bond of tetrahedron structure. Studies have shown that ${ }^{[12-15]}$ when the content of $\mathrm{TiO}_{2}$ is less, $\mathrm{TiO}_{2}$, mainly in the four-coordinate Ti-O bond structure-based, completely is miscible with the glass; With the increase of the content of $\mathrm{TiO}_{2}$, the amount of four coordinated Ti-O bond reduces, while the number of six-coordinated Ti-O bond increases; when $\mathrm{TiO}_{2}$ reaches a certain level, six-coordinated Ti-O bond reduces, but the four-coordinated Ti-O bond increases. Thus, the crystallization activation energy increased first and then decreased with increasing $\mathrm{TiO}_{2}$ content. This is the reason that the glass crystallization temperature decreased first and later elevated with increasing $\mathrm{TiO}_{2}$ content in the glass. When the glass melt cools from the hightemperature, the base glass is mainly characterized by the spatial structure of the mesh. $\mathrm{TiO}_{2}$ presents in the tetrahedral structure among the glass network. During the cooling process the viscosity of the glass is high, atoms have no time to rearrange to form a new crystal structure, and thus $\mathrm{TiO}_{2}$ keep the tetrahedral network status from high temperature to room temperature. Although $\mathrm{TiO}_{2}$ is present in the tetrahedron structure of the glass network, but its structure is not $\mathrm{q}$ stable state, but the hexacoordination structure $\left[\mathrm{TiO}_{6}\right]$ is its stable structure, and therefore when the temperature reaches a certain condition, it will transform into a stable hexacoordination $\left[\mathrm{TiO}_{6}\right]$ structure. Because the $\left[\mathrm{SiO}_{4}\right]$ tetrahedron structure is different with the hexacoordination $\left[\mathrm{TiO}_{6}\right]$ structure and $\mathrm{Ti}^{4+}$ ions have the stronger ability to capture oxygen atoms off than the $\mathrm{Si}^{4+}$ ions, so it is possible that $\mathrm{TiO}_{2}$ can separate out together with other types of oxides from the silicon-oxygen network to precipitate crystals in a certain condition. The crystal structure transformation of $\mathrm{TiO}_{2}$ from $\left[\mathrm{TiO}_{4}\right]$ to $\left[\mathrm{TiO}_{6}\right]$ is a process of transition from the high-energy state to a low energy state, to prompt the glass separating, to reduce the interface energy and the activation energy required in the process of nucleation and crystallization, so the glass transition temperature and 
crystallization temperature decrease too. But when $\mathrm{TiO}_{2}$ is more, it has a tendency to agglomerate, not only would not achieve the role of nucleating agents in a certain extent, but also the opposite effect. Because $\mathrm{TiO}_{2}$ is an intermediate oxide to form the network, when its content is more, it has a tendency to cluster, especially when the content of nucleating agent $\mathrm{TiO}_{2}$ is more, a lot of segregation of $\mathrm{TiO}_{2}$ will happen. When the content of $\mathrm{TiO}_{2}$ and the temperature reach a certain level, it will precipitate as a stable rutile phase. When $\mathrm{TiO}_{2}$ content is more, the main tetrahedral structure of $\mathrm{TiO}_{2}$ is present in the glass network, and its structure and glass structure tetrahedron are exactly the same, so in some degree it might repair the broken silicon-oxygen bond to reconnect, and cause the crystallization temperature to increases with increasing $\mathrm{TiO}_{2}$ content.

\section{Results}

1. The activation energy of glass ceramics firstly reduced then increased with $\mathrm{TiO}_{2}$ content, but the crystallization index reduced after the first increase.

2. The crystallization activation energy of glass was affected by the $\mathrm{TiO}_{2}$ content, it can change by adding a nucleating agent or changing a base glass composition to achieve optimal composition ratio to improve the crystallization index, reduce the crystallization activation energy.

3. The amount of $\mathrm{TiO}_{2}$ content has an optimum value of about $8 \%$, the minimum activation energy of crystallization for $225.87 \mathrm{KJ} \cdot \mathrm{mol}^{-1}$, the maximum crystallization index of 1.95 .

\section{References}

1. Yuan J, Tang L Y, Xu C, et al. A DTA Study on Crystallization Behavior of $\mathrm{Li}_{2} \mathrm{O}-\mathrm{Al}_{2} \mathrm{O}_{3}-4 \mathrm{SiO}_{2}$ Glass [J]. Journal of Wuhan University of Technology, 1997, 19(4):75-77.

2. Yang Q H, Jiang Z H. Study on kinetics criterion for glass crystallization $[\mathrm{J}]$. Journal of the Chinese ceramic society, 1994, 22(5):419-42.

3. Uhlmann D R. Glass formation [J]. Non-Cryst Solids, 1977, 25-43.

4. Hu L L, Jiang $\mathrm{Z} \mathrm{H}$. A new criterion for crystallization of glass [J]. Journal of the Chinese ceramic society, 1990, 18(3): 315-321.

5. J.A.Augis, J.E.Bennett. Calculation of the Avrami Parameters for Heterogeneous Solid State Reactions Using A Modification of the Kissinger Method [J]. Journal of Thermal Analysis, 1978, 13(2):283-292.

6. M.L.Ovegoglu, B.Kuban, H.Ozera. Characterization and Crystallization Kinetics of A Diopside Based Glass-Ceramic Developed from Glass Industry Raw Materials [J]. Journal of the European Ceramic Society, 1997, 17(7):957-962.

7. S.Kim, Y.C, Kim. Using isothermal kinetic results to estimate the kinetic triplet of the pyrolysis of high density polyethylene [J]. Jnal. Appl. Pyrolysis, 2005,73(1):117-121.
8. J.H.Flynn. The temperature integral-its use and abuse [J]. Thermochim.Acta., 1997, 300(1):83-92.

9. H.E.Kissmger Reaction of kinetics in differential thermal analysis [J]. Anal. Chem., 1957, 29(11): 1702-1706.

10. T.Ozawa. Estimation of activation energy by isocoversion methods [J]. Thermochim. Acta. 1992, 203(1):159-165.

11. T.Ozawa. Kinetics of glass crystallization $[\mathrm{J}]$. therm. Anal. 1970, 31(2):301-305.

12. Li B W, Du Y S, Zhang X F. Influence of $\mathrm{Na}_{2} \mathrm{O}$ on the Microstructure and Mechanical Properties of Glass-Ceramics Based on Baiyunebo Tailing [J]. Materials Review, 2012, 26(16): 129-131.

13. Liu H Q, Wei G X, Liang Y. Crystallization Behavior of Glass-ceramics from Arc-melting Slag of Waste Incineration Fly Ash [J]. Journal of Chongqing Jianzhu University, 2012, 34(2):121125 .

14. Dai W B, Li Y, Chang D Q. Effects of heat treatment process on the microstructure and properties of BOF slag based glass ceramics [J]. Journal of University of Science and Technology Beijing, 2013, 35(11):1507-1512.

15. Li J, Mei Y Z, Luo Z W. Preparation of transparent glass-ceramics with high crystallinity $[\mathrm{J}]$. The Chinese Journal of Nonferrous Metals, 2012, 21(6):1450-1456. 